ISBN: 978-980-427-021-5

\title{
Sincelejo: Distrito especial de paz para la reconciliación, reconstrucción social y Calidad de Vida
}

\author{
Emperatriz Ramírez Coronado ${ }^{1}$, Eidy María Contreras Banques², \\ Mórela Cristina Meza Mercado 3
}

\section{Resumen}

El conflicto armado en Colombia se caracteriza por ser cambiante y dinámico en el tiempo, en el territorio y en cada una de las consecuencias que este fenómeno puede causar. Casi siempre es difícil es determinar unas causas u orígenes, pues como se arguye anteriormente este ha sido heterogéneo con el paso de los años, hechos que convierten a Colombia en el país con el conflicto más prolongado y antiguo en toda la región suramericana. Con el paso de los años el país se ha visto sumido en diferentes problemas como consecuencia del conflicto armado. Es fácil mencionar algunos ejemplos, producto del conflicto: expansión territorial y crecimiento militar de las guerrillas, el surgimiento de los grupos paramilitares, la crisis del Estado, la irrupción y propagación del narcotráfico. Por esta razón, es necesario plantear una posición teórica y práctica con respecto al tema de reconstrucción y reconciliación que se dará en la implementación y desarrollo de los distritos especiales de paz procurando mejorar la calidad de vida de las personas, reconociendo un proceso complejo donde se involucra una perspectiva de carácter social y político del cual se puede concebir varios momentos transformación donde se reincorpore la sociedad que ha sido víctima de violencia, teniendo como premisa, encaminar a dichas sociedades hacia la

1 Corporación Universitaria del Caribe, Colombia. Correo electrónico: emperatriz. ramirezc@cecar.edu.co, Especialista en Procesos Familiares y Comunitarios, Humanidades. Grupo de Dimensiones Humanas, línea de investigación: "Gestión ciudadana y del Estado en el desarrollo social, organizacional y comunitario"

2 Corporación Universitaria del Caribe, Colombia. Correo electrónico: Eidy.contreras@ cecar.edu.co, Especialista en Procesos Familiares y Comunitarios, Humanidades, Grupo de Dimensiones Humanas, línea de investigación: "Gestión ciudadana y del Estado en el desarrollo social, organizacional y comunitario"

3 Corporación Universitaria del Caribe, Colombia. Correo electrónico: morela.mezam@ cecar.edu.co. Especialista Gerencia Pública, Humanidades, Grupo de Dimensiones Humanas, línea de investigación: "Gestión ciudadana y del Estado en el desarrollo social, organizacional y comunitario" 
reconstrucción, mejoramiento de la calidad de vida de diferentes escenarios de convivencia entre los grupos armados, sociedad y víctimas. El presente artículo es resultado de análisis realizados en el marco de procesos de prácticas estudiantiles del programa de Trabajo Social, apoyados desde el paradigma cuantitativo, de tipo descriptivo.

Palabras clave: reconstrucción, reconciliación, conflicto, calidad de vida, psicosocial.

\section{INTRODUCCIÓN}

El presente artículo es una síntesis basada en el desarrollo del posconflicto y la implementación de distritos especiales de paz, teniendo como ciudad piloto la Sincelejo capital del departamento de Sucre, el cual muestra en detalle la situación que atraviesa este municipio como receptor de familias desplazadas por el conflicto armado de la región caribe y el resto del país.

En la primera parte se aborda un marco conceptual, definiendo el conflicto armado y cómo ha sido su evolución en Colombia, los procesos de reconciliación y reconstrucción, la metodología que se aborda es una revisión bibliográfica para así justificar dichos conceptos.

En la segunda parte se hace un panorama de cómo está el municipio y cuál es el impacto psicosocial que implica la implementación de los distritos de paz, los beneficios y problemáticas que podría acarrea; de esta forma se puede abordar el impacto psicosocial que trae consigo el postconflicto, este apartado está basado en un análisis de la situación.

En la última parte del artículo se hacen propuestas desde el punto de vista personal con el fin de aportar un enfoque diferente al que se hace en la implementación de los distritos de paz que se está tomando como punto de partida la ciudad de Sincelejo; y finalmente se exponen las conclusiones mostrando de forma sintetizada las principales enseñanzas de todo el documento.

\section{CONFLICTO ARMADO Y CALIDAD DE VIDA}

La violencia sociopolítica y el conflicto armado interno en Colombia han producido en las víctimas y en la sociedad en su conjunto una serie de daños materiales e inmateriales, entre ellos la pérdida de los referentes organizativos de la sociedad (valores democráticos, ética de la vida en común, solidaridad, bien común, etc.), secuelas sobre la salud física y mental de las víctimas, sobre la economía, sobre las instituciones y relaciones sociales, y sobre la cultura y sus diferentes manifestaciones. 
Este tipo de violencia quiebra la posibilidad de despliegue de las capacidades de disfrute y búsqueda del bienestar propio y colectivo. Las situaciones que imponen la violencia sociopolítica desbordan en gran medida la capacidad del ser humano de sortear las dificultades por sí mismo, no obstante su capacidad de resiliencia; por lo tanto, para superarlas y continuar su vida, es necesario el desarrollo de acciones en ámbitos como la justicia, la protección, los medios de subsistencia básicos y el apoyo para retomar la construcción del proyecto de vida individual, familiar y comunitario, así como del tejido social que privilegie la convivencia armónica y equilibrada basada en el respeto a la dignidad humana.

Las bases fundamentales para lograr una salud mental, y bienestar colectivo son lesionadas por la violencia, lo cual exige que un país como Colombia en el que ha sido un continuo la violencia armada, priorice todas aquellas medidas de atención para reparar los daños. Son varias las generaciones de colombianos y colombianas que han vivido la violencia del conflicto armado y esta cadena de sufrimiento configura un impacto transgeneracional que afecta gravemente un proyecto de país basado en el fortalecimiento de la democracia y el respeto a las libertades y derechos de sus asociados.

Es sabido que los efectos sobre la salud física y mental no conciernen solamente a las manifestaciones somáticas, emocionales y del comportamiento que presentan las personas como consecuencia de los hechos violentos, sino que deben ser considerados teniendo en cuenta los factores sociales, ambientales, políticos, económicos y culturales existentes, derivados o producidos como consecuencia del conflicto armado; es decir, con un enfoque psicosocial.

Existen diversos conceptos relacionados al término 'Calidad de Vida', utilizándose indiscriminadamente para referirse a estilos de vida o patrones de vida. La calidad de vida, entendida como el vivir bien ha sido ampliamente estudiada desde las ciencias humanas y de la salud, desde lo políti$\mathrm{co}$, social y económico hasta en la medicina y psicología. En esta gama de aproximaciones, existen estudios sobre calidad de vida y economía, bienestar social, bioética, calidad de vida y salud, incluyendo diversos tests y baterías psicológicas para medir el nivel de calidad de vida (Vallejo Bravo, 2016).

El impacto psicosocial "tiene que ver con la situación inicial en la que las personas y comunidades se encuentran luego de la circunstancia de violación de derechos que hayan vivido; ésta, en la mayoría de los casos, se caracteriza por la desorientación, por no entender qué paso, por no creer 
que haya sido posible que esos hechos hubieran sucedido, por la pérdida de previsibilidad en el mundo: es casi un estado de confusión generalizado.

Al hacer estas distinciones se busca ubicar al acompañante en relación con las estrategias de acción que se planteen, lo que permite agudizar la mirada de acuerdo con las necesidades de atención que requieren las personas, ya que si se habla de impacto habría que pensar en estrategias y herramientas de atención en crisis, unos primeros auxilios emocionales o un apoyo inicial para tomar decisiones a fin de "saber qué hacer, a dónde ir, a quién buscar, con quién hablar", mientras que, frente al daño, se deben plantear procesos de acompañamiento que contemplen acciones terapéuticas individuales y colectivas, lo mismo que de reconstrucción o fortalecimiento de redes sociales, y la reconstrucción como sujetos sociales, de derechos, políticos, es decir, que aporten al reconocimiento de su dignidad."

Partir de una mirada integral en tanto el término psicosocial parte en esencia de un reconocimiento de que lo psicológico y social son un continuum superando la división que han establecido las disciplinas. Para el caso colombiano el contexto de la violencia sociopolítica se impone como el referente para comprender los impactos en las víctimas.

Superar la visión dicotómica entre lo mental/ emocional y lo físico y, entre lo individual y contextual (político, social y cultural), para lograr comprensiones sistémicas de las dificultades que presentan las personas víctimas a diferencia de explicaciones lineales, por ejemplo, "está triste porque fue desplazada"; este tipo de afirmaciones dificultan el conocimiento de las personas y la búsqueda de las alternativas posibles de apoyo.

Reconocer que un hilo orientador para explorar el efecto que tiene en las personas victimas la atención psicosocial, es el mundo emocional, en él se percibe un nuevo estado de bienestar o un cambio frente al sufrimiento infligido. Por lo tanto es necesario reconocer y explicitar con las victimas cómo las diferentes formas de atención de diversos actores e instituciones responsables y comprometidas en la reparación, favorecen sentires o emociones más positivas a partir de nuevas experiencias, narrativas y significados sobre la sociedad, el Estado y sobre sí mismos, que marcan diferencias evidentes y concretas con la tristeza, rabia, impotencia y sufrimiento vividos por la violencia, la impunidad, la inequidad y la indiferencia.

Es imprescindible partir de una concepción del ser humano como agente de su propia vida, responsable tanto de su propio destino como de los procesos sociales de los que participa. La atención se debe distanciar del asistencialismo o la prestación de un servicio para recrear la identidad 
de sujeto de derechos de la población.

Superar una concepción reduccionista de los impactos o de la realidad de las personas que han sido víctimas al normalizar su situación a partir de lo dado, es decir, al asumir la realidad presente como un orden natural, perdiendo de vista la posibilidad de transformación y el valor de la capacidad humana para realizar cambios.

Por lo tanto, es fundamental reconocer en los individuos y en las comunidades algunas necesidades básicas psicosociales, entre las que se encuentran el trato digno, la seguridad y la protección, el reconocimiento de la experiencia traumática, el acceso al ejercicio de sus derechos como víctimas, la participación en la toma de decisiones que afectan sus vidas, la atención en los procesos de duelo (apoyo emocional individual mediante grupos de apoyo o apoyo terapéutico) y el fortalecimiento de los lazos de soporte afectivo y social.

Reconocer que las víctimas son sujetos de derechos, titulares de derechos y libertades reconocidos en la Constitución y tratados internacionales, frente a los cuales el Estado tiene la obligación insoslayable de restablecerles en las condiciones personales y sociales que las dignifiquen y, reconocer que las víctimas del conflicto armado son personas a quienes se les ha sometido a situaciones extremas de violencia, sometimiento y perturbación de sus referentes más fundamentales de vida.

Los desplazados han sido tratados peyorativamente, discriminándolos por su condición, misma que nunca buscaron, siendo los protagonistas de diversas estadísticas e indicadores por parte de las agencias gubernamentales y otras de tipo independiente que han limitado su intervención y resultados a meros números como indicadores. Con la revisión teórica hecha anteriormente se entiende que calidad de vida no solo se restringe a la satisfacción de necesidades básicas y en este sentido no puede hablarse de calidad de vida porque se dio un suministro de medicinas, dinero y en algunos casos vivienda que, si bien son satisfactores que estabilizan el estado físico, la calidad de vida sigue estando en juego por el estado emocional de la víctima, producto del evento traumatizante (Vallejo Bravo, 2016).

En Colombia dar una definición de conflicto armado supone a simple vista un término fácil de describir y connotar, ya que la gran parte de nuestra historia como nación soberana se ve impregnada de violencia, un resultado inequívoco del conflicto armado; quizás definir el conflicto en nuestro país sea totalmente diferente a como se define en la academia, unas simples letras, palabras o párrafos son una pequeña parte de lo que es en su esencia 
un fenómeno social como lo es el conflicto armado.

Al abordar las diversas definiciones propuestas en diferentes apartados, se define el conflicto como "una relación social por la que dos o más colectividades aspiran a satisfacer intereses o demandas incompatibles, utilizando sus desigualdades de poder para mantener actuaciones antagónicas o contrapuestas, recurriendo, en último extremo, a la violencia. Cuando el conflicto se desarrolla entre actores internacionales lo denominaremos un conflicto internacional". (Djalili, 2016)

En este artículo hablaremos en primera instancia sobre el conflicto interno. Es importante mencionar que el conflicto armado en Colombia como un mal social se ha venido presentando desde hace décadas y es necesario mostrar cuáles son sus causas y cuestionarse el por qué ha sido un proceso que se ha mantenido hasta nuestros días.

Según (Centro de Memoria Histórica, 2016):

la evolución del conflicto armado sus continuidades y cambios está relacionados con un sinnúmero de factores. Entre ellos se encuentran la persistencia del problema agrario; La irrupción y la propagación del narcotráfico; las limitaciones y posibilidades de la participación política; las influencias y presiones del contexto internacional; la fragmentación institucional y territorial del Estado. Finalmente, también han estado relacionados, con los cambios y transformaciones del conflicto, los resultados parciales y ambiguos de los procesos de paz y las reformas democráticas.

Todo esto ha hecho que nos toque aceptar con profunda tristeza que la situación de orden público en Colombia es bastante complicada, puesto que el enfrentamiento de las fuerzas regulares del Estado con los demás grupos armados al margen de la ley diariamente tiene como invitados de primera fila a personas integrantes de la población civil.

Como se ha mencionado anteriormente existen autores que refuerzan la idea de que el conflicto armado interno es un fenómeno muy complejo que abarca diferentes factores.

El conflicto armado interno que desde hace muchos años se libra en el territorio de la República de Colombia tiene varias dimensiones, y en cada una de ellas son fácilmente apreciables múltiples consecuencias dañinas.

En ese conflicto se interrelacionan diversos factores que tienden a nutrir su reproducción: las ideologías justificadoras de la violencia, las exclusiones políticas, económicas y sociales, la producción y el tráfico de drogas, el comercio ilícito y la proliferación de armas, el peso de otros intereses económicos y el empleo de la guerra como modus vivendi. 
Todos estos males se han visto reflejados en diferentes grados en la gran mayoría de los pueblos e inclusive los municipios de nuestro país; en nuestro caso nos acercaremos al municipio de Sincelejo, que está atravesado por una serie de anomalías provocadas por el conflicto entre ellas la recepción de familias desplazadas por la violencia.

\section{DIAGNÓSTICO DEL CONTEXTO}

Según la oficina de atención a víctimas del conflicto armado, Colombia afronta uno de los conflictos armados más largos y complejos de la región, de hecho, por cerca de cinco décadas, han sido reiteradas prácticas violatorias de los Derechos Humanos, que han ocasionado la muerte de miles de civiles; el exterminio de partidos políticos, grupos y líderes de oposición que han dejado, en todo su territorio, incontables víctimas e innumerables heridas sin cicatrizar que impiden cerrar el ciclo de la violencia.

El municipio de Sincelejo no es ajeno a estas problemáticas, entre el 2000 y 2012 víctimas procedentes de diferentes sitios cercanos a este municipio, fueron enajenados de sus propiedades, desarraigados de su terruño y tejido social, producto de la ola de violencia acrecentada en el país por los actores del conflicto armado.

Según (Unidad para la Atención y Reparación Integral a las Víctimas, 2012) el lugar de residencia de las victimas encontramos registradas un total de 9.727 personas residentes en el departamento; los principales municipios donde se concentra el mayor número de víctimas están: Sincelejo 4.493 víctimas que representan el 46.19\%; Ovejas con 718 personas víctimas que integran el 7.38\%; Corozal 667 víctimas representan el 6.86\%, San Onofre, Sucre y Sincé ocupan el $12.48 \%$.

Según (Agencia de la ONU para los Refugiados. ACNUR, 2005) en cuanto a los grupos de autodefensa, el origen de estas estructuras está estrechamente ligado al narcotráfico y a las estructuras armadas creadas alrededor de esta actividad. Hay que recordar que durante la década de los ochenta, muchos personajes asociados al narcotráfico adquirieron tierras, en municipios vecinos y la ciudad de Sincelejo que eran utilizadas como zonas de recreo y refugio, además de asegurar el tráfico de drogas por los corredores de la zona. Estas agrupaciones armadas se encargaban de "amparar las propiedades adquiridas y para ello se organizaban en pequeñas estructuras". 


\section{¿Qué es un proceso de reconciliación y reconstrucción?}

El concepto reconciliación, sería entonces "un proceso extremadamente complejo y multifactorial, realizado a largo plazo (que puede implicar incluso varias generaciones), que tiene muchas posibles vías metodológicas de abordaje y que, igualmente, tiene un número importante de vías terapéuticas multidimensionales" (Martínez López, 2002).

Conocemos entonces la reconstrucción como: "el proceso que consiste en evocar recuerdos y tratar de reunirlos para completar un concepto o el conocimiento de un hecho". Esta técnica es muy utilizada por los cuerpos de investigación criminal, para intentar recrear asesinatos y atracos de gran envergadura, a partir de los detalles recogidos por los oficiales de policía y los detectives. Por otro lado, la psicología se apoya en la reconstrucción.

Una vez determinado lo que entendemos por Reconciliación es preciso hacer referencia a situaciones que se han tomado tradicionalmente como Reconciliación; pero, que en realidad no se ajustan a la complejidad del proceso tal como se ha definido para efectos de este estudio, tal como lo sugiere (Schreiter, 1998) la reconciliación entonces esta direccionada hacia los procesos sociales, teniendo en cuenta procesos derivados de actos violentos.

Denominamos como principios básicos de un proceso de reconciliación, todos aquellos elementos que se deben tener en cuenta para dar sustento al proceso y cuya presencia marca el éxito o fracaso del mismo.

Al asumir un proceso de Reconciliación, cada sociedad debe hacerse un juicio interno sobre cuáles de estos principios va a privilegiar; puesto que los procesos de reconciliación se mueven en un continuo, en el cual deben definir, por ejemplo, cuánta verdad se desea conocer, cuánta justicia aplicar, hasta dónde llega el perdón y cómo se va a mantener la memoria.

Esta decisión no resulta fácil, pero para ello la sociedad debe medirse en sus necesidades, expectativas, deseos, aspiraciones y proyecciones. De tal forma, que más allá de la coexistencia pacífica, se consolide un verdadero proceso de reconciliación y con el tiempo con seguridad se de paso al perdón (Bueno Cipagauta, 2016).

La reconciliación sin un proceso de reconstrucción se puede interpretar como un proceso de paz a la ligera. Si no se da un periodo de reconstrucción la reconciliación trae consigo problemas a la hora de olvidar periodos de violentos. Generalmente quienes hacen uso de este tipo de propuestas o tienen la intención de ayudar aquellos que vivieron en entornos violentos, que lo hacen estar reacios a perdonar los actos que de alguna u otra forma 
afectaron a una o varias familias. La reconciliación es un proceso que requiere tiempos y espacios propios, así como el respeto por la dignidad humana y el duelo que pueden experimentar las víctimas. La reconstrucción busca la restauración de vidas humanas, especialmente las de aquellos que más han sufrido. Todo proceso de reconstrucción y restauración demanda tiempo, lo cual, si bien puede provocar que los diferentes actores y participantes en el proceso se sientan inseguros u obligados a tomar esta opción, resulta condición necesaria para que puedan comenzar una nueva vida.

La reconciliación y reconstrucción como alternativa a la libertad. La libertad no es una alternativa, sino un requisito previo para la misma. La libertad es con respecto sólo a la situación de violencia, sino también de las estructuras y procesos que permiten y promueven la violencia.

Para hablar de reconciliación y reconstrucción del tejido social, no basta sólo con asumir la verdad, se requiere también de la adopción de medidas que busquen mejorar las condiciones de las víctimas, subsanar el dolor y el daño resarciendo económica, social y moralmente. La reconstrucción no será posible en la medida que se especifiquen, analicen y erradiquen las causas del conflicto. De lo contrario esto no será más que una tregua (Bueno Cipagauta, 2016).

La reconciliación y reconstrucción, no es un proceso que involucre solo mecanismos técnicos, sino, que se logre mediante negociaciones; es un tanto grupal como individual, para poder entender y superar el conflicto, partiendo de un pleno convencimiento por desechar los actos violentos y la venganza como mecanismo para la restauración.

\section{Impacto psicosocial que tendrá la ubicación de distrito especial de paz en el municipio de Sincelejo}

Como se ha expuesto anteriormente los daños que puede causar el conflicto armado son irreversibles en su mayoría, así como explica la oficina de atención a víctimas del conflicto armado.

La violencia sociopolítica y el conflicto armado interno en Colombia han producido en las víctimas y en la sociedad en su conjunto una serie de daños materiales e inmateriales, entre ellos la pérdida de los referentes organizativos de la sociedad (valores democráticos, ética de la vida en común, solidaridad, bien común, etc.), secuelas sobre la salud física y mental de las víctimas, sobre la economía, sobre las instituciones y relaciones sociales, y sobre la cultura y sus diferentes manifestaciones.

Teniendo en cuenta esto es inhumano pensar lo que son capaces otros seres humanos dañando a una sociedad que no es culpable de la diferencia 
ideológica del país, o que simplemente no debe ser sometida por un grupo subversivo con el fin de suplir sus intereses, demostrando así que el interés particular prima sobre el general, llegando a un conflicto armado interno y las consecuencias que tiene esto sobre la población civil son enormes: amenazas, asesinatos, desapariciones, desplazamiento forzado, son algunos de los peligros a los que se vieron expuestos los habitantes de los diferentes municipios que han toma do a Sincelejo como punto de encuentro para huir de la violencia.

La enorme afluencia de foráneos de bajos recursos económicos, más la población flotante que se estima en 18.000 personas que llegan a la ciudad diariamente a demandar bienes y servicios, ha traído consigo un crecimiento acelerado, no planificado y, más aún, que escapa a todo intento planificador, multiplicándose las dificultades para controlar los procesos de urbanización, lo cual genera la proliferación de asentamientos precarios de origen informal: invasiones en zonas de riesgo, laderas, zonas de rondas hidráulicas, de manejo y preservación ambiental, causando deterioro ambiental, problemas acelerados de movilidad y

Un alto déficit de espacio público -cuantitativo y cualitativo-, así como la provisión del mismo para un futuro próximo. Por consiguiente, se entiende que la población de Sincelejo, con al menos una necesidad básica insatisfecha sea del $40.4 \%$ en el área urbana y del $61.2 \%$ en el área rural.

El distrito especial de paz de Colombia, es muy significativo, porque según argumentó en la audiencia pública realizada en la capital de Sucre el día de hoy llama la atención el gran porcentaje de víctimas que ha dejado la violencia durante más de cinco décadas en todo el departamento de Sucre y la Región Caribe en general. El posconflicto se deberá articular de manera estratégica con los planes departamentales, para que dentro de ellos existan rutas de acción que incluyan reparación y reconciliación para la sociedad sucreña. Sincelejo debe apropiarse del compromiso que se ha hecho el Gobierno Nacional con las mujeres víctimas del conflicto armado. Es decir, que desde esta ciudad debemos impulsar una agenda de política territorial construida con enfoque de género, pluricultural e intergeneracional, en la que las mujeres de nuestra región sean protagonistas en la construcción de una nueva Colombia.

Según (Schreiter, 1998), la población civil no sólo sufre la violencia generada por el conflicto armado, sino que está sometida a otros dos niveles de violencia: el abandono y la inoperancia de las instituciones que deberían atenderla, y el silencio y el estigma por parte de la sociedad. Estos tres ni- 
veles de violencia tienen efectos sobre la salud mental y sobre la calidad de vida de los individuos y las comunidades, expuestos de una manera u otra al conflicto.

\section{Acompañamiento psicosocial a la población de Sincelejo}

Para comprender mejor la situación del conflicto armado en el municipio de Sincelejo es importante tener en cuenta el concepto de acompañamiento psicosocial. Según el centro internacional para la justicia transicional (2009), aunque no existe una definición única, la atención psicosocial puede entenderse, en términos generales, como un proceso de acompañamiento, individual, familiar o comunitario; orientado a hacer frente a las consecuencias de un impacto traumático y a promover el bienestar y el apoyo emocional y social del beneficiario, estimulando el desarrollo de sus capacidades.

Desde la alcaldía municipal de Sincelejo y con el apoyo de la oficina de atención a víctimas del conflicto armado se han hecho una serie de actividades y propuestas que a simple vista suelen ser una forma de restaurar una sociedad, en primer lugar se hace necesario una caracterización de la comunidad víctima del conflicto armado asentados en la cabecera municipal de Sincelejo, identificar la problemática de mayor incidencia y afectación dentro de la comunidad objeto de estudio, teniendo en cuenta los factores psicosociales y salud del individuo, diseñar una propuesta que en un lapso mejore las condiciones de vida de la comunidad. objetivo:

En el proyecto de Ley 40 de 2015, artículo $1^{\circ}$, menciona el siguiente

Otorgar a la ciudad de Sincelejo la categoría de Distrito Especial de Paz de Colombia y dotarla de facultades e instrumentos legales, que le permitan cumplir las funciones y prestar los servicios a su cargo; así como promover el desarrollo integral de su territorio para contribuir al mejoramiento de la calidad de vida de sus habitantes.

Con esta iniciativa, el Partido Liberal busca que se le otorgue a la ciudad de Sincelejo la categoría de Distrito Especial de Paz de Colombia y dotarla de instrumentos legales, que le permitan cumplir sus funciones y prestar los servicios a su cargo.

Para la reconstrucción del tejido social y la calidad de vida de las personas podemos definir el tejido social como:

El entramado de relaciones cotidianas que implican a su vez relaciones de micro vínculos en un espacio local y social determinado como lo es el barrio, donde sus habitantes como cultura, recreación y capital social al relacionarse entre ellos para obtener algún fin determinado y al interaccionar con su entorno y medio macro-socia (Castro \& Angélica, 2001). 
Es por lo anterior que el tejido social supone pensar en una serie de relaciones dinámicas mutuas y de influencia recíproca entre los habitantes de una vereda, barrio, municipio o localidad y que están cumpliendo una función de apoyo, soporte y movilización de los elementos fisiológicos y piscoafectivos a la persona.

Es importante establecer una serie de metas puntuales de corto, mediano y largo plazo para los programas y componentes de atención psicosocial a las víctimas del conflicto y los procesos de reconstrucción de la calidad de vida de las personas, de manera que sea posible garantizar que la población objetivo goce efectivamente de sus derechos a la dignidad e integridad física, psicológica y moral.

Es entonces la reconciliación y reconstrucción es una fuente para la solución de los conflictos y una extensión de la firma que traerá consigo la tan anhelada paz en Colombia, es por ello que se necesita la participación de diferentes actores sociales en el municipio tales como hombres, mujeres, niños de las comunidades educativas, los líderes y agremiaciones comunitarias y campesinas, las minorías étnicas.

Con estos actores se puede construir un proceso social que involucre no solo a un segmento de la sociedad, sino que se encamine a la reconciliación y reconstrucción de las víctimas, victimarios y las personas que de alguna u otra forma no han participado de forma directa del conflicto pero hacen parte de la sociedad que ha visto el sufrimiento de las diferentes comunidades extraditadas hacia otros municipios lejos de la guerra y lejos de los conflictos en los que la población civil nunca ha deseado tener participación.

Para iniciar el desarrollo y reconocimiento de las personas que participan directamente en los distritos de paz es necesario realizar censos que permitan identificar esta población víctima de la violencia y de actores armados, es decir, es necesario seleccionar e identificar quienes han sido víctimas y victimarios, de esta manera se pueden identificar las zonas de las cuales han salido todas estas familias y por qué eligen a Sincelejo como punto de encuentro para alejarse del conflicto.

Así mismo consagra en su artículo 3 los principios rectores que rigen la creación de los distritos Especiales, destacando para el caso que nos ocupa los siguientes:

- Autonomía. Las entidades territoriales gozan de autonomía para la gestión de sus intereses dentro de los límites de la Constitución y la ley. 
- Descentralización. La distribución de competencias entre la Nación, entidades territoriales y demás esquemas asociativos se realizará trasladando el correspondiente poder de decisión de los órganos centrales del Estado hacia el nivel territorial pertinente, en lo que corresponda, de tal manera que se promueva una mayor capacidad de planeación, gestión y de administración de sus propios intereses, garantizando por parte de la Nación los recursos necesarios para su cumplimiento.

- Sostenibilidad. El ordenamiento territorial conciliará el crecimiento económico, la sostenibilidad fiscal, la equidad social y la sostenibilidad ambiental, para garantizar adecuadas condiciones de vida de la población.

- Participación. La política de ordenamiento territorial promoverá la participación, concertación y cooperación para que los ciudadanos tomen parte activa en las decisiones que inciden en la orientación y organización territorial.

- Solidaridad y equidad territorial. Con el fin de contribuir al desarrollo armónico del territorio colombiano, la Nación, las entidades territoriales y las figuras de integración territorial de mayor capacidad política, económica y fiscal, apoyarán aquellas entidades de menor desarrollo relativo, en procura de garantizar el acceso equitativo a las oportunidades y beneficios del desarrollo, para elevar la calidad de vida de la población.

- Gradualidad y flexibilidad. El ordenamiento territorial reconoce la diversidad de las comunidades y de las áreas geográficas que componen el país, por tanto, ajustará las diferentes formas de división territorial. Las entidades e instancias de integración territorial se adaptarán progresivamente, para lo cual podrán asignárseles las competencias y recursos que les permitan aumentar su capacidad planificadora, administrativa y de gestión. En el caso de las instancias de integración, las competencias y recursos serán asignados por las respectivas entidades territoriales que las componen.

- Paz y convivencia. El ordenamiento territorial promoverá y reconocerá los esfuerzos de convivencia pacífica en el territorio e impulsará políticas y programas de desarrollo para la construcción de la paz, el fortalecimiento del tejido social y la legitimidad del Estado.

- Equidad social y equilibrio territorial. La ley de ordenamiento territorial reconoce los desequilibrios en el desarrollo económico, so- 
cial y ambiental que existen entre diferentes regiones geográficas de nuestro país y buscará crear instrumentos para superar dichos desequilibrios. Por ello la Nación y las entidades territoriales propiciarán el acceso equitativo de todos los habitantes del territorio colombiano a las oportunidades y beneficios del desarrollo, buscando reducir los desequilibrios enunciados. Así mismo, los procesos de ordenamiento procurarán el desarrollo equilibrado de las diferentes formas de división territorial (Congreso de la República Colombiana, 2015).

Por tanto, es necesario que en el proceso se deje muy claro cuáles serán las directrices que se van a seguir, pues dentro del desarrollo de la ubicación estratégica de los puntos de atención para esta población es necesario identificar los que realmente fueron participes del conflicto y no sean unos privilegiados más que otros. Tal es el caso de Sudáfrica, donde se privilegió la verdad en detrimento de la justicia, lo cual es válido en la medida en que respondió a la necesidad de hacer frente a crímenes atroces donde la mayoría de la población ya sea en un bando o en otro se veía seriamente implicada.

Para el caso de la ciudad de Sincelejo presenta en la actualidad el siguiente contexto que le permite ser un distrito de paz y un punto piloto para el desarrollo del mismo:

Una enorme afluencia de foráneos de bajos recursos producto del desplazamiento forzado y la incapacidad de la ciudad para acogerlos con la oportunidad y las condiciones que reclama la dignidad humana.

Necesidad de implementar entre los habitantes de la ciudad una cultura de convivencia ciudadana que supere realmente y de manera definitiva los problemas que genera el desplazamiento forzado.

Necesidad inminente de una cultura política que llene el vacío producido por un sistema educativo que hace abstracción de lo auténticamente social y convierte al desplazado, al marginado y al desmovilizado en ciudadanos de ninguna parte. Un crecimiento acelerado y no planificado de la ciudad generando problemas socioeconómicos (desempleo, empobrecimiento...), ambientales, de riesgo al ubicarse en zonas no aptas para habitar, entre otros.

La ciudad no cuenta con una estructura operativa y funcional que tenga representación en una entidad capaz de liderar y articular las acciones y competencias sobre el espacio público y sus equipamientos. 
Así las cosas, queda claro que la ciudad de Sincelejo con las actuales transferencias y recursos propios no alcanzará a solucionar los enormes problemas que afronta en un horizonte previsible.

Si se quiere que el desplazamiento, en cualquiera de sus orígenes, no se convierta en una cultura sino en una oportunidad de construir una nueva ciudad de personas libres y honestas, necesita que se la constituya en Distrito Especial de Paz, para que apoyada por una constitucional y novedosa figura administrativa se levante como ejemplo para las ciudades que soportan similares circunstancias.

\section{RECOMENDACIONES}

Cuando se analiza una problemática de este tipo, donde la población civil es la principal afectada, nos damos cuenta que es difícil establecer soluciones a un conflicto que conlleva a otros males sociales como la delincuencia, la drogadicción, la prostitución, es por tanto que las instituciones se comprometan en brindar un apoyo integral sostenible y acabar con lo enfermedad que el país lleva por décadas.

Este artículo muestra que sí es posible ofrecer servicios de salud mental, económica, social y que le permita a la población afectada contar con recursos que los lleve a desarrollarse como personas que progresan y aportan a la sociedad y no son catalogados como un problema.

La necesidad de crear nuevas políticas públicas multidimensionales que incluyan la ayuda humanitaria, el acceso a la salud, a la comida y a la vivienda sólo en primera instancia, pero generando, así mismo, programas integrales que incentiven y promuevan el bienestar subjetivo de las víctimas. La calidad de vida de un desplazado es un tema que debe tratarse desde esa mirada global que permita fomentar una adecuada intervención en el momento que se requiera. Las entidades encargadas de este evento deben formular sus políticas teniendo en cuenta la situación emocional del desplazado y sabiendo que es un proceso complejo que va más allá de la reparación física de los elementos perdidos puesto que se trata también de generar una estabilización psico-socio-económica. Estas tres dimensiones deben "ir de la mano" para un restablecimiento adecuado de los derechos de las personas víctimas del desplazamiento. Entonces, la calidad de vida desde el punto de vista multidimensional, permite forjar un tejido que articula acciones enfocadas a la situación social del individuo con el entorno social al que pertenece.

En la población objetivo se ha visto el compromiso de los entes gubernamentales en mejorar la situación y a pesar de los escasos recursos 
o de la misma corrupción que aqueja a gran parte de la región caribe, es posible aportar a la mejora de hombres y mujeres que son importantes para la sociedad.

Por esta y muchas otras razones es necesario hacer no solo de Sincelejo, sino de las ciudades foco de personas y familias víctimas de la violencia un punto de partida para la ejecución de nuevos sueños, metas y objetivos que los lleven a desarrollarse de manera integral, aportando así a la sociedad un crecimiento no solo en número de población sino de personas que desean hacer del futuro de los municipios y ciudades de Colombia algo mejor.

\section{CONCLUSIONES}

En Colombia la condición de desplazados es un problema real donde las víctimas de este flagelo han tenido que sufrir el destierro obligatorio de su territorio, soportando además la discriminación social y la readecuación en un espacio donde no les brindan las garantías para restablecer su cotidianidad y ante todo su estabilidad física y emocional.

La calidad de vida de los desplazados en Colombia ha sido vulnerada y no se ha manejado adecuadamente aun cuando existen ingentes esfuerzos gubernamentales y de ONG'S por ayudar a este tipo de víctimas, cuya atención se ha limitado a aspectos básicos de subsistencia, que, aunque importante, no son suficientes. El daño psicológico en un desplazado está hecho, el trauma vivido por el evento ha generado en éste diferentes síntomas de malestar psicológico que pueden degenerar en consecuencias y hasta en enfermedad mental permanente y en conductas lesivas para sí mismo y su entorno. Por tanto, la intervención social y psicológica es un evento necesario y de obligatoria incorporación en los programas de ayuda y atención, que no se ha realizado en Colombia

Finalmente se puede decir que el conflicto armado es un problema que se ha manifestado en el territorio colombiano en diferentes grados, dejando a sus habitantes con problemas no solo físicos y mentales.

Los distritos especiales de paz buscan organizarse como áreas metropolitanas, siempre que existan unas relaciones físicas, sociales y económicas que den lugar al conjunto de dicha característica y coordinar el desarrollo del espacio territorial integrado por medio de la racionalización de la prestación de sus servicios y la ejecución de obras de interés metropolitano. Dividiendo así el territorio nacional en localidades, de acuerdo a las características sociales de sus habitantes y atribuir competencias y funciones administrativas. 
A pesar de que se han realizado diferentes iniciativas en el municipio aun no es posible demostrar con exactitud si los habitantes tienen un bienestar integral, si el plan piloto será aceptado por los nativos de Sincelejo, es más, muchas personas aún no tienen claro la posición que deben tener como actores dentro del posconflicto en Colombia, pues cabe resaltar que la paz no es solo de las personas que deciden reinsertarse a la vida civil, sino que involucra a toda la sociedad, pues somos de alguna u otra forma culpables de no dar oportunidades a quienes verdaderamente lo necesitan, el estado y los entes privados que han podido participar en la solución del conflicto no se han apersonado del proceso, pues muchos piensan que no les compete el cuidado y desarrollo de la sociedad civil.

El conflicto armado colombiano no solamente constituye en sí mismo un factor de riesgo para la salud mental de las personas expuestas, sino que además genera condiciones en las cuales emergen otros factores de riesgo como la delincuencia y la prostitución que adicionalmente contribuyen al deterioro de la salud y la calidad de vida de las personas y las comunidades, por esta razón es importante apoyar el desarrollo y solución del posconflicto con proyectos como estos que le permiten a las personas desechadas por la sociedad reincorporarse y poder hacer algo diferente con una visión y objetivos marcados que le permitan avanzar, es por esto que es necesario restaurar la salud mental no solo de los actores de la guerra, sino también del público en general que necesita evolucionar.

Se resalta que el acompañamiento psicológico es una gran herramienta que mejora las posibilidades brindar servicios de salud mental de calidad y de forma efectiva a la población afectada por el conflicto.

\section{REFERENCIAS BIBLIOGRÁFICAS}

Agencia de la ONU para los refugiados. ACNUR. (4 de Julio de 2005). Obtenido de http://www.acnur.org/t3/uploads/media/COI_2188.pdf?view=1.

Alto Comisionado para los Derechos Humanos Oficina en Colombia. (5 de Julio de 2005). Obtenido de http://www.hchr.org.co/publico/pronunciamientos/ ponencias/po0564.pdf.

Bueno Cipagauta, M. A. (13 de Febrero de 2016). La reconciliación como un proceso socio- político. Aproximaciones teóricas. Obtenido de http://www.colombiaaprende.edu.co/html/mediateca/1607/articles-168269_archivo.pdf

Castro, N., \& Angélica, G. (2001). «Tejido social y Construcción de Sociedad». ONG Cordillera. Centro de Estudios Municipales. . Obtenido de www.siciedad.cl./ acción/portada/pagina.asp

Centro de Memoria Histórica. (4 de Junio de 2016). Centro Nacional De Memoria Histórica . Obtenido de http://centrodememoriahistorica.gov.co/descargas/informes2013/bastaYa/capit 
Congreso de la República Colombiana. (15 de Agosto de 2015). Obtenido de http://190.26.211.102/proyectos/index.php/textos-radicados-senado/pl2015-2016/469

Djalili, M.-R. (2016). Reflexiones sobre una tipología de los conflictos en el tercer mundo. En Reflexiones sobre una tipología de los conflictos en el tercer mundo (págs. 23-33). Barcelona: Fontamara.

Martínez López, M. (2002). El poder pacifista. Barcelona: AIPAZ.

Schreiter, R. J. (1998). Violencia y Reconciliación: misión y ministerio en un orden social en cambio. Santander: Sal Terrae.

Unidad para la Atención y Reparación Integral a las Víctimas. (30 de Junio de 2012). Sucre: Informe Departamental de Hechos Victimizantes a 2012. Obtenido de http://rni.unidadvictimas.gov.co/sites/default/files/Documentos/Sucre. pdf

Vallejo Bravo, I. D. (26 de Julio de 2016). Amérique latine histoire \& mémoire. Obtenido de https://alhim.revues.org/3822\#ftn1 